\title{
Reshaping the Global Climate Change Regime through the Paris Agreement
}

\author{
Theodore Okonkwo*
}

\begin{abstract}
The Paris Agreement on Climate Change which aimed at halting climate change and limiting global warming to 1.5 degrees Celsius, remains the most important piece of international diplomacy in years, since the Kyoto Protocol of 1992 and the Copenhagen Accord (which endorsed the continuation of the Kyoto Protocol) 2009. The signing of the Paris Agreement underlies the fact that climate change remains one of the greatest challenges of our time and calls for a strong political will to urgently combat climate change in accordance with the principle of common but differentiated responsibilities and respective capabilities. This article looks at Paris Agreement's resolve to peak global greenhouse-gas emissions as soon as possible and also undertakes a cursory examination of the global climate regime. The article also examines how the problem of climate change has altered since the 2009 Copenhagen Accord and concludes by emphasizing the need to take the Paris Agreement forward in spirit.
\end{abstract}

Keywords: 1.5 degree Celsius, Copenhagen Accord, Greenhouse gas, Kyoto Protocol, Paris Agreement

* University of Port Harcourt, Port Harcourt, Nigeria, finefinishltd@yahoo.com 


\section{Introduction}

Energy needs are crucial to human existence. However, developing nations tend to depend on the sources of energy that emit carbon dioxide to sustain their economic activity, including the sustaining of national defence, ${ }^{1}$ agricultural requirements such as production of fertilizers, building and running of irrigation, farm ploughing, planting of large-scale crops, harvesting of seeds such as rice and millets, and spraying of pesticides. They also depend on $\mathrm{CO} 2$ emitting equipment for communication, transportation, carriage of goods and refrigeration. ${ }^{2}$

The demand for energy is rising across the world and the pressure to produce more goods and services is causing environmental challenges. ${ }^{3}$ In the developing continents of South America and Africa, the need for local sources of home used energy is causing deforestation and bush burning. More than $81 \%$ of global energy is obtained from carbon dioxide emitting fossil fuels and over $90 \%$ of the world's energy is derived from non-carbon-neutral energy sources. ${ }^{4}$ These concerns have led to several scientific studies designed to find the consequences of the increase of carbon dioxide in the atmosphere. ${ }^{5}$ The results of the empirical studies have shown that industrial emissions of carbon dioxide are linked to global warming. However, the scientific findings have been a source of complicated debates; For example, Donald Trump, the President of

1 M TBoykoff, and J M Boykoff, Balance As Bias: Global Warming and the US Prestige Press, 14 GlobalEnvironmental Change, 125 - 136, (2004).

2 America's Climate Choices Panel on Advancing the Science of Climate Change National Research Council, Advancing the Science of Climate Change (Washington, D.C. The National Academies Press, 2010).

3 Aant Elzinga, Shaping Worldwide Consensus: the Orchestration of Global Change Research (Elzinga and Landström eds. 223-255, 1996).

4 D M Kahan. et. al The Tragedy of the Risk-Perception Commons: Culture Conflict, Rationality Conflict, and Climate Change, Temple University Legal Studies Research Paper No. 2011-26 (2011) https:/ / ssrn.com/abstract=1871503.

5 Kahan Dan M. Climate-Science Communication and the Measurement Problem. Advances in Pol. Psych., 36, 1-43 (2015) https:// ssrn.com/abstract $=2459057$. 
the United Sates has tagged it as a 'fake science'. ${ }^{6}$ Nonetheless, the emphasis of global warming science and politics are in the fields of 'Adaptation, Mitigation, Finance, Technology and Losses.'7 In all spheres of human endeavours, it is generic knowledge that is needed to sustain a healthy climate for safe living, for all is the essence of human livelihood. It is this realization that is driving the climate change initiatives. The Paris Agreement is one such global stepping stone. ${ }^{8}$ The quest for sustainable global climate is one of the reasons why there is a strong desire to make the Paris Agreement work.

Meyer has described the Paris Agreement as 'the most important piece of international diplomacy in years. ${ }^{9}{ }^{\text {Fabius }}{ }^{10}$ described it as 'ambitious and balanced'11,'historic turning point', 12 in the attempt by international comity of nations to control the global mean surface-temperature change. The Agreement included 'not only the rich, northern nations that put most of the carbon into the atmosphere, but also the rapidly developing southern states whose emissions could soon dwarf the rest of the world.'13 The Agreement set a pushy peak of 1.5 degrees Celsius and underpinned the earlier

6 Bodansky Daniel, The Copenhagen Climate Change Conference-A PostMortem, 104 American Journal of International Law, (2010).

7 Posner Eric A and Sunstein Cass R, Climate Change Justice. University of Chicago Law and Economics, Online Working Paper No. 354 (August 2007).

8 IdId, at 5.

9 Robinson Meyer, A Readers Guide to the Paris Agreement, The Atlantic, available at https://www.theatlantic.com/science/archive/2015/12/areaders-guide-to-the-paris-greement/420345. (Last accessed on 15 June 2017).

${ }^{10}$ Nations Climate Change Conference (COP21) held in Paris, France, from November 30 to December 15, 2015.

${ }^{11}$ Doyle Allister and Lewis Barbara, World Seals Landmark Climate Accord, Marking Turn from Fossil Fuels (2015) Reuters, Thomson Reuters, May 1, 2016 available at http://www.reuters.com/article/us-climatechangesummit-idUSKBNOTV04L20151212. (Last accessed on 17 June 2017).

12 IdId.

${ }^{13}$ Robinson Meyor, Is Hope Possible After the Paris Agreement, The Atlantic, April 8, 2017, available at https:// www.theatlantic.com/ science/archive/2015/12/can-we-hope-after-the-parisagreement/420174. (Last accessed on 18 June 2017). 
international efforts of controlling the effects of global warming and climate change surface temperature, below two degrees Celsius. This article argues that while the agreement is seen as 'historic' and 'turning point in the climate crisis,' there are still several complex questions that need to be determined:

- How much should the countries limit global warming?

- How quickly will countries stop emitting greenhouse gases?

- Who should bear the climate finance burden and who receives the funding?

- How will countries control and monitor their emission reductions?

- Who should be the watch-dog of countries to ensure compliance?

- Who takes responsibility for the loss and damage caused by climate change?

- Who is responsible for protecting the climate?

This article will attempt to answer these questions. The Paris Agreement is not meant to solve all the climate change problems. Without doubt, it serves as acknowledgement of problem and concrete efforts towards real discussions to solve the complex climate change questions. In doing this, real and committed funding is required in order to achieve the overall goals set at the 2015 United Nations Climate Change Conference in Paris. The reality is that the carbon dioxide caps contained in the Paris Agreement will not keep the planet to 1.5 degrees Celsius of warming; they will not even keep it to two. Christiana Figueres ${ }^{14}$ argued that the two-degree cap is not even realizable. ${ }^{15}$ There is, however, hope that despite the unresolved questions, the Paris Agreement has achieved one great feat, that of involving the world's most powerful countries into agreeing on the dangers of the greenhouse effect. Between 1992 and 2009, the United Nations'

14 The United Nations lead climate change negotiator and the impresario of Paris.

${ }^{15}$ Elizabeth Kolbert, The Weight of the World: Can Christiana Figueres Persuade Humanity to Save Itself? (The New Yorker 3August 24, 2015). 
attempt to bring the world powers to subscribe to cutbacks on greenhouse gases failed to yield positive outcome prior to the launching of the Paris COP21 in 2015. Kyoto 1997 tried to get China, India, and the United States to cut their emissions, but this failed. Twelve years later in Copenhagen, the attempt was futile and failed. But then, Paris made all the difference. The success of Paris COP21 could be aligned with the fact that prior to the Conference, the United Nations requested every state party to the UNDCCC 'to prepare its own individual climate-change-fighting plant'. About 150 countries responded to the model, including the United States and China. Thus, a 'new era in climate diplomacy' emerged, which 'imposes a new cycle, a new calendar of cutbacks, onto the future.' Can countries totally stop emitting carbon by 2060? Is it possible? This article argues otherwise, as these questions could only be determined by several factors that shape humanity, 'the ethnics of food, of oil, of technology, of economic security, of democratic republics and command capitalism, of colonialism and indigenous peoples, of who in the world is rich and who in the world is poor.'16 This article argues that despite man's efforts to rein in the environment and protect it from despoliation, countries still squabble over borders, vaunt military might, and despise refugees in their midst. The Paris Accord is not in itself a one-off solution to the climate change challenges; the international community will still be doing more talks and taking more action in the future to take care of the increase in earth's average surface temperature due to rising levels of greenhouse gases.

\section{International Efforts in the context of Climate Change Regime}

In 2009, the international community meeting at Copenhagen ${ }^{17}$ agreed that the global temperature average should be limited to the two degrees Celsius over pre-industrial levels. This below two degrees Celsius has not been achieved. The Accord which is not

16 Robinson Meyer (n 6).

17 The Fifteenth Session of the Conference of Parties, 7-18 December 2009 acknowledged that climate change is one of the greatest challenges of our time (FCCC/CP/2009/L.7, December 18, 2009). 
legally binding had the United States, China, India, South Africa, and Brazil not agreeing to commit to a binding successor to the Kyoto Protocol, which according to Gerard had its round ended in 2012.18 The Accord declares public approval of the Kyoto Protocol. ${ }^{19}$ It underscores that climate change remains one of the greatest issues of our time and stresses a strong political will to urgently combat climate change in accordance with the principle of common but differentiated responsibilities and respective capabilities.

It expresses that,' enhanced action and international cooperation on adaption is urgently required to reduce vulnerability and build resilience in developing countries, especially in those that are particularly vulnerable, especially Least Developed Countries (LDCs), Small Island Developing States (SLDS) and Africa,'20 and asserts that 'developed countries shall provide adequate, predictable and sustainable financial resources technology, and capacity-building to support the implementation of adaptation action in developing countries. ${ }^{21}$ It provides that Annex 1 Parties 'commit to implement individually or jointly the quantified economy-wide emissions targets for 2020.'22

The representatives of 196 countries gathered at the 21st Conference of the parties of the UNFCC in Paris and adopted by consensus on 12 December, 2015, the Paris Agreement, which is an agreement within the United Nations Framework Convention on Climate Change (UNFCCC) dealing with greenhouse gases emissions mitigation, adaptation, and finance starting in the year 2020.23 The agreements' main aim is to keep a global temperature

18 Wynn Gerard, What was Agreed and Left Unfinished in U.N. ClimateDeal, Reuters,May 20, 2017, http://www.reuters.com/article/us-climatecopenhagen-issues-idUKTRE5BJ0X520091220. (Last accessed on 28 June 2017).

191997 Kyoto Protocol to the UN Framework Convention on Climate Change, 2303 UNTS 148/[2008]ATS 2/37/LM 22[1998], UNDOCFCCC/CP/1997/7/Add. 1. Dec 10, 1997, 37 KM 22 (1998).

20 Decision 3, id.

21 Decision 3, id.

22 Id.

23 FCCC/CP/2015/L.9?Rev. 1. 
rise this century well below two degrees Celsius and to drive efforts to limit the temperature increase even further to 1.5 degrees Celsius above pre-industrial levels.' The Paris Agreement on climate change officially entered into force on November 4, 2016, after 55 nations representing 55 percent of the total global greenhouse gas emissions, deposited their instruments of ratification, acceptance or approval with the UN SecretaryGeneral.24

The Paris Agreement articulates actions and policies to be taken by nations to contain climate change challenges before the end of the century. Governments agreed on a number of issues: mitigation, that is reducing emissions, ${ }^{25}$ transparency and global stock take, ${ }^{26}$ adaptation, ${ }^{27}$ loss and damage, ${ }^{28}$ role of cities, regions, and local authorities, $^{29}$ support, ${ }^{30}$ capacity-building, ${ }^{31}$ stock-take and ratcheting. ${ }^{32}$ The Paris Agreement furthers the UNFCCC and is remarkable in that it succeeded in bringing together all the nations of the world into a universal agreement to tackle climate change and 'adapt to its effects' with an undertaking to support the developing countries in implementing the content of the Agreement. Thus, this single document provides a new road map in the international climate action effort. Apart from the Agreements main objective of consolidating the international climate action to keep the temperature rise below two degrees Celsius above pre-industrial levels, and to work towards attaining the 1.5 degrees Celsius, the Agreement further agrees to 'strengthen the ability of countries to deal with the impacts of climate change.' In order to attain the overall objectives, the Agreement requires that necessary funding, cutting-edge technology framework and enhanced capacity building framework should be established to

24 As of March 12017194 UNFCCC members have signed the Agreement and 153 countries have joined the Paris Agreement.

25 Paris Agreement, art. 6, April 162016.

26 Article 13, id.

27 Article 7, id.

28 Article 8, id.

29 Preamble to the Paris Agreement.

30 Article 9, id.

31 Article 16, id.

32 Article 14, id. 
support 'action by developing countries and the most vulnerable countries, in line with their own national objectives.' Article 13 of the Agreement made provision for enhanced transparency framework for action and support, in order to build mutual trust and confidence and to promote effective implementation.

By Article 4(2) provisions, each state party shall prepare, communicate and maintain successive nationally determined contributions that it intends to achieve and further pursue domestic mitigation measures with the aim of achieving the objective of such contributions. By 2018, Parties to the Agreement shall take stock of the collective efforts in relation to progress towards the goal set in the Paris Agreement and to inform the preparation of Nationally Determined Contributions. It is provided that a global stock-take shall be taken every five years to assess the collective efforts towards attaining the overall goal of the Agreement and to inform further individual actions by Parties.

\section{Analysis of the Global Climate Change Regime}

The global climate change regime is currently trending on the platform of the Paris Climate Agreement. Thus, different views and opinions have been expressed by several writers and commentators. Writing on the New York Times, Anna Dubenko ${ }^{33}$ cited David Harsanyi, who stated that,'our massive over indulgences have created a catastrophic future'. ${ }^{34}$ For Keith Hennessey, the 'Paris Agreement is completely meaningless no matter what we do'. ${ }^{35}$ This article however, argues differently and supports the global view that the Paris Agreement remains the only viable and credible platform on which to tackle the problems of climate change. This is reality, notwithstanding the criticism that has followed the Agreement. There are bound to be 'passionate

33 Anna Dubenko, Right and Left React to the Paris Climate Agreement News, New York Time, June 4, 2017, https:/ / /www.nytimes.com/ 2017/ 06/ 04/us/politics/paris-treaty-re-actions.html.

34 David Harsanyi, Democrats Have Lost On Climate Change, And It $\square$ s Their Own Fault. The FEDERALIST, note 39 above.

35 Keith Hennessey, Why the Paris Climate Agreement is Completely Meaningless no Matter What We Do, Id. 
advocates' and critics of 'policy changes' which usually provokes fierce political battle over trivially small policy impacts.

The key aim and objective of the Paris Agreement is to halt climate change and limit global warming to 1.5 degrees Celsius. This should not be ignored as this is' a first step toward an end state that all agree would be quite a large change'. Despite criticisms, the Agreement symbolizes a significant direction of change that would push a possible 'future movement' that will gravitate toward that quantitatively significant end goal, which is curtailing global warming to 1.5 degrees Celsius. Surprisingly, some high profile political leaders still remain sceptical about this ambitions Agreement. President Donald Trumps scepticism with regard to the Paris Agreement can be gauged from his act of withdrawing the United States from the Agreement. While not supporting Donald Trump's action, this article argues that while applauding the content and spirit of the Agreement, there are still problems and issues that would need to be addressed. Some of these problems and issues are in the structure and language of the text. It contains many areas of ambiguous language and 'flexibility' for countries to reinterpret their only loosely binding quantitative commitments to reduce greenhouse gas emission.

Another problem is that of political interest. President Trump made it a campaign issue that his country would withdraw from the Agreement, if elected as the President of the United States. After assuming office, he executed this. Thus, both President Obama's signing of the Paris Agreement on climate change and President Trump's withdrawal are for political interests. However, it might be, this article maintains the argument that the Agreement is a modest first step that is aimed at progress in the future. Again for the developing countries and small island nations, their future in this Agreement is not so certain and assured due to non-availability of funds to tackle the climate change impact as contained in the Agreement. These are well founded fears, because the developed countries are not forthcoming with financing they promised them, more so, the withdrawal of the United States from the Agreement means that the country could no longer honour its financial commitment. Without funding from the developed countries, 
developing and the small island nations could not be sufficiently empowered to fulfil their deepening future commitment.

There is another problem which this article identifies, and that is the process of pledge and view' which requires each country to submit Intended Nationally Determined Contribution (INDC), which could constitute the agreement. This creates a problem, because there are no standards to govern these INDCs, which means that most countries could compromise and not submit accurate INDCs or nothing at all. Party countries could modify their INDCs to suit them and there are no sanctions for countries which fall short. The Agreement contains no process to scrutinize or challenge INDCs submission which may fall short of the expected progress. The idea of pledge and view was to make compliance with Agreement voluntary but this idea does not work for developing countries which still rely heavily on fossil-fuel infrastructure for economic development. To change this pattern means slowing down their growth, and this is not acceptable as these nations lack access to renewable energy.

To expect developing nations to rely on expanding energy access and to reduce emissions, conflicts with their pursuit of economic development, which would definitely not reduce emission cuts. There is also glaring international apathy of some countries which choose to abandon the call to embrace clean energy. This is not out of lack of interest, but due to unavoidable costs of technology which always has been central to climate policy and to the failure of effort at international cooperation. Unfortunately, Paris did not solve this problem.

There is also what has been described as peer-pressure. ${ }^{36}$ This peerpressure according to Oren Cass, ${ }^{37}$ has made developing nations submit uniformly meaningless commitments. According to him, China promised to reach peak emission around 2030, right when it was expected to anyway. India made no emissions commitment but pledged to improve its energy efficiency less quickly than it

36 Oren Cass, The Paris Agreement Got the Logic of Climate Action All Wrong, Good Riddance, LOS ANGELES TIMES, June 2, 2017, available at https://www.latimes.com.

37 Id. 
already was improving. Many countries offered no meaningful baseline for comparison. Pakistan only committed to reduce its emissions after reaching peak levels to the extent possible. 38

Notwithstanding all these constraints, this article argues that the Paris Agreement is not a worthless or meaningless accord. It succeeded in bringing the world together to discuss a common issue that does not respect international boundaries. Problems and criticisms of Paris cannot and does not overshadow its achievements. For the first time ever, the whole world got together at a conference to take climate change impact seriously. The deal, that is Paris Agreement is commendable despite its shortcomings. The world has committed to a global climate regime that addressed the climate change impact. This is the first and major step, identification of a common problem. Full compliance and commitment with INDCs no doubt might not be perfect, but would definitely reduce global temperatures by the year 2100, even if it is not by 1.5 degrees Celsius, any lesser reduction of greenhouse gas emissions is acceptable and will progress in the future. Oren Cass has stated that analysis at the Massachusetts Institute of Technology indicated that full compliance with all pledges would reduce temperature in the year 2100 by only 0.2 degrees Celsius.

Finally, this article would want countries that are parties to the Agreement to domesticate the Agreement. Most countries constitutions require their national parliament to approve any international treaty by a two-thirds majority, before such treaty becomes law. Not domesticating the Paris Agreement at various national levels would definitely create a backlash and lack of consensus support back home, would lead to delinquency, which has no place in international law, as nations are required to honour their international obligations and commitment.

\section{Analysis of Case Laws on Climate Change}

There is general consensus among intellectuals regarding the threat of global warming and climate change to future health of humans and plant species across the world. Hence, litigations have been on

$38 \mathrm{Id}$. 
the rise regarding the enforcement of the rights to safe and healthy environment, in tandem with the yearning needs for action. In Massachusetts v. Environmental Protection Agency, ${ }^{39}$ twelve states in the United States took an action against the United States' Environmental Protection Agency (EPA) to coerce the agency to regulate carbon dioxide and other greenhouse gases (GHGs). The issues for determination by the Supreme Court were:

a) Whether the petitioners had standing.

b) Whether carbon dioxide is air pollutant causing air pollution.

c) Whether the EPA Administrator may decline to issue emission standards for motor vehicles on the basis of policy considerations not enumerated in Section 202(a)(1) of the EPA enabling law.

The Supreme Court weighed the circumstances of the case in accordance with the Clean Air Act ${ }^{40}$ and voted 5 to 4 in favour of the petitioners. The court acknowledged that the injuries connected with climate change are serious and well recognized. The impending risks of catastrophic harms, though remote, are nonetheless real. The court reiterated that:

The case has been argued largely as if it were one between two private parties; but it is not. The very elements that would be relied upon in a suit between fellow-citizens as a ground for equitable relief are wanting here. The State owns very little of the territory alleged to be affected, and the damage to it capable of estimate in money, possibly, at least, is small. This is a suit by a State for an injury to it in its capacity of quasi-sovereign. In that capacity the State has an interest independent of and behind the titles of its citizens, in all the earth and air within its domain. It has the last word as to whether its mountains shall be stripped of their forests and its inhabitants shall breathe pure air.

39 Massachusetts v. Environmental Protection Agency549 U.S. 497 (2007).

40 Clean Air Act,42 U.S.C. § 7521(a)(1). 
In Urgenda Foundation $v$. The State of the Netherlands, ${ }^{41}$ the plaintiff sought to hold the Dutch Government liable for not being able to take reasonable steps to reduce greenhouse gas emissions that cause dangerous climate change. The plaintiffs sought declaration that:

a) Global warming of more than two degrees Celsius will lead to a violation of fundamental human rights worldwide.

b) The Dutch State is acting unlawfully by not contributing its proportional share to preventing a global warming of more than two degrees Celsius.

c) The Dutch State should drastically reduce Dutch CO2 emissions even before 2020 to the level that has been determined by scientists to be in line with less than two degrees Celsius of global warming, that is, to reduce Dutch emissions by $40 \%$ by 2020 below 1990 levels.

The Hague District Court held that the Netherlands must take reasonable steps to prevent the looming dangers posed by climate change. It went on to emphasize that the government owes duty of care to the plaintiff and therefore is under legal obligation to protect and improve the living environment. The court said:

[I]t has been established that any anthropogenic greenhouse gas emission, no matter how minor, contributes to an increase in $\mathrm{CO} 2$ levels in the atmosphere and therefore to hazardous climate change.

In summary, the Court established a satisfactory underlying link between Dutch emissions, global climate change, and the effects. The Court determined that the Dutch government must reduce CO2 emissions by a minimum of $25 \%$ (compared to 1990) by 2020 , to fulfil its obligation to protect and improve the living environment, against the imminent danger caused by climate change.

41 Urgenda Foundation v. The State of the NetherlandsC/09/456689/HA ZA 13-1396 (June 24, 2015). 
Further to the above cases, American jurisprudence is replete with climate-related litigation. This article examines few post-2016 cases in this sphere. In League of Conservation Voters $v$. Trump, ${ }^{42}$ ten environmental groups filed a lawsuit in the federal district court for the District of Alaska challenging the portions of President Trump's executive order of April 28, 2017 on implementing an America-First Offshore Energy Strategy that purported to eliminate protections for lands in the Arctic and Atlantic Oceans. President Obama withdrew the lands from future oil and gas leasing in January 2015 and in December 2016, pursuant to presidential authority, under the Outer Continental Shelf Lands Act (OCSLA). The complaint noted that in withdrawing the lands, President Obama and the White House had cited a number of factors supporting the withdrawal, including the need to make a transition from fossil fuels to address climate change, stresses to Arctic species resulting from climate change, and the contribution of withdrawn Atlantic Ocean canyons to climate stability, as well as threats to the canyons from climate change. In their complaint, the environmental groups asserted that President Trump's executive order exceeded his constitutional authority and intruded on congressional authority under the Property Clause of the Constitution in violation of the separation of powers doctrine. They also asserted that his actions exceeded authority granted by OCSLA, which they argued did not authorize presidents to re-open lands for disposition, once they had been withdrawn.

In Resolute Forest Products, Inc. v. Greenpeace International, ${ }^{43}$ the federal district court for the Southern District of Georgia transferred forest-products companies lawsuit alleging federal and state Racketeer Influenced and Corrupt Organizations Act (RICO) claims against Greenpeace International and other organizations (Greenpeace), to the Northern District of California. The forestproducts companies asserted that the defendants illegally attacked their forestry practices, and also suggested that, the companies

42 League of Conservation Voters v. TrumpNo. 3:17-cv-00101 (D. Alaska, filed May 3, 2017).

43 Resolute Forest Products, Inc. v. Greenpeace InternationalNo. CV 11671 (S. D. Ga. May 16, 2017). 
created climate change risks by harvesting the Boreal forest. The Georgia federal court found that the companies alleged loss of Georgia customers had not occurred in its district and that a trip by the defendants to the district did not give rise to the plaintiffs claims. Because two Greenpeace employees who were integral to the plaintiffs forestry campaign were based in San Francisco, the court concluded that a substantial part of events giving rise to the plaintiffs $\square$ claims occurred in the Northern District of California and that venue was therefore proper.

The New York Supreme Court on April 19, 2017 awarded more than $\$ 20,000$ in attorney fees and litigation costs to the Competitive Enterprise Institute (CEI), which brought a lawsuit against the New York Attorney General under the New York Freedom of Information Law (FOIL). CEI filed the proceeding after the Attorney General denied its FOIL request for common interest agreements with private parties and other state attorneys general regarding climate change investigations. In awarding fees to CEI, the court cited its November 2016 decision in favour of CEI and said that law of the case precluded further examination of the Attorney General's arguments that CEI had not substantially prevailed or had not met statutory requirements for eligibility for fees. The court said that the Attorney General had stonewalled rather than provide the straightforward response to which CEI was entitled and that an award of substantial attorney fees was particularly appropriate to promote FOILs purpose and policy. ${ }^{44}$

In the case of Truck Trailer Manufacturers Association, Inc. v. EPA, ${ }^{45}$ the D.C. Circuit granted EPAs motion to hold the cases challenging its greenhouse gas emissions and fuel efficiency standards for new large and heavy-duty vehicles in abeyance while EPA considered a request for reconsideration of the standards from one of the petitioners. The court ordered that the cases be held in abeyance pending further order of the court and directed the parties to file motions to govern further proceedings by July 20, 2017. The court said it would not address a request to defer deadlines in the

44 Competitive Enterprise Institute v. Attorney General of New York, No. 5050-16 (N.Y. Sup. Ct. Apr. 19, 2017).

45 Truck Trailer Manufacturers Association, Inc. v. EPANos. 16-1430 \& 161447 (D.C. Cir. May 8, 2017). 
standards because the stay factors had not been addressed in the request.

Three trade groups in the case of Juliana $v$. United States, ${ }^{46}$ moved to withdraw from the federal lawsuit in which young people alleged that the United States, the president, and other federal defendants had violated their constitutional rights by allowing greenhouse gases to accumulate in the atmosphere. The federal district court for the District of Oregon granted the three groups - National Association of Manufacturers (NAM), American Petroleum Institute (API), and American Fuel and Petrochemical Manufacturers (AFPM) permission to intervene as defendants in January 2016, over the plaintiffs opposition. In their motions to withdraw, NAM, API, and AFPM indicated that just as a plaintiff retains rights to decide not to pursue particular claims, so could an intervener decide that it no longer wishes to pursue currently the particular interests and rights that led to intervention in a particular case. Noting that the plaintiffs had opposed their intervention in the first place, the groups asserted that withdrawal would serve judicial economy and would not prejudice remaining parties. On June 5, the plaintiffs filed a response to NAMs motion to withdraw, saying that while they did not outright oppose the motion, they believed it should only be granted with conditions, including that the withdrawal be with prejudice and that NAM be required to pay plaintiffs' attorneys fees and costs attributable to NAMs participation in the case.

The trade group's motions to withdraw were filed less than a month after a federal magistrate judge recommended rejecting a request for immediate appeal of the district court's denial of the defendants and intervener-defendants motions to dismiss the lawsuit, and after the federal defendants and the intervenerdefendants filed objections to the magistrate's recommendation. The federal defendants contended that the magistrate judge's recommendation was primarily based on an incorrect perception that additional fact-finding is necessary, while largely ignoring the purely legal Constitutional, jurisdictional, and separation-ofpowers issues that make continued litigation improper. The federal

46 Juliana v. United StatesNo. 6: 15-cv-01517-TC. 
defendants also objected to and asked for reconsideration of the magistrate judge's denial of a motion to stay the litigation. The intervener-defendants who argued that the case checks all of the boxes for immediate review focused their objections on the issue of whether the plaintiffs' claims raised a non justifiable political question, an issue that the federal defendants did not identify for certification, focusing instead on standing and the validity of the plaintiffs due process and public trust claims. The plaintiffs responses to the objections to magistrate judge's findings and recommendations argued that the magistrate judge had properly concluded that no controlling questions of law were present and that there were no substantial grounds for differences of opinion on the plaintiffs' standing, their due process rights, or their public trust claim. (The plaintiffs also asserted that the intervener's withdrawal would obviate the need for review of their objections.) The plaintiffs also defended the denial of a stay; they asserted that the federal defendants' only evidence of prejudice resulting from moving forward with the litigation was general grievances about the normal rigors of responding to discovery and that, on the other hand, plaintiffs would be irreparably injured because carbon dioxide levels increased with each passing day. ${ }^{47}$

The Colorado Oil and Gas Conservation Commission (COGCC) in the case of Colorado Oil $\mathcal{E}$ Gas Conservation Commission v. Martinez,48 asked the Colorado Supreme Court to review an intermediate appellate court's decision holding that COGCC had wrongly denied a rulemaking petition on the grounds that the requested COGCC to take action outside its statutory authority. The rulemaking petition, which was submitted by a group of young people, sought to bar issuance of permits for oil and gas drilling unless best available science demonstrated that there would not be adverse impacts to the environment or human health or a contribution to climate change. COGCC said that the appellate court's interpretation of the Oil and Gas Conservation Act improperly required the agency to prioritize environmental concerns over other policy considerations that the Act required

47 Juliana v. United States, No.6:15-cv01517-Tc

48 Colorado Oil \& Gas Conservation Commission v. MartinezNo. 17SC 297,Colo. petition and letter dated May 18, 2017. 
COGCC to take into account. COGCC said this novel interpretation conflicted with Supreme Court and other appellate court precedent, was at odds with the Act's actual language, and implicitly endorsed the public trust doctrine, which had not been adopted in Colorado. The particular issue COGCC asked the court to consider was whether, when the Commission engages in rulemaking, is it permitted to disregard the Act's policy of fostering oil and gas development in Colorado? COGCC and the Colorado Attorney General decided to pursue the appeal despite objections by Governor John W. Hickenlooper. In response to a request from the governor's office not to pursue the appeal, the attorney general sent a letter asserting that the governor did not have authority to direct COGCC's decision-making and that the attorney general had independently determined that the issues raised in the case should be determined by the Colorado Supreme Court

In this case, ${ }^{49}$ the Western Organization of Resource Councils and Friends of the Earth asked the D.C. Circuit Court of Appeals to reactivate their appeal of a district court August 2015 decision dismissing their action alleging that federal agencies failed to conduct an adequate analysis of the environmental effects including climate change-related effects of the federal coal leasing program. In January 2016, Secretary of the Interior Sally Jewell directed the U.S. Bureau of Land Management to prepare a programmatic environmental impact statement (PEIS) and paused issuance of new coal leases until the PEIS was completed. In June 2016, the D.C. Circuit granted a joint request by the two conservation groups and the federal defendants to hold the groups' appeal in abeyance while the PEIS was prepared. On March 29, 2017, Secretary of the Interior Ryan Zinke revoked Secretary Jewell's order. The conservation groups said that Secretary Zinke's action restored the federal coal leasing program to its status at the time of the district court decision and their noticing of the appeal. They therefore asked the D.C. Circuit to end the abeyance, establish a briefing schedule, and calendar the case for oral argument.

49 Western Organization of Resource Councils v. Zinke, No. 15-5294, D.C. Cir. (May 26, 2017). 
The Center for Biological Diversity in the case of Center for Biological Diversity v. U.S. Department of Interio ${ }^{50}$ filed a Freedom of Information Act (FOIA) lawsuit against the U.S. Department of the Interior, EPA, the U.S. Department of Energy, and the U.S. Department of State in the federal district court for the District of Columbia seeking to compel the agencies to provide records of any directives or communications barring or removing climate changerelated words or phrases from formal communications. The Centre for Biological Diversity also sought production of information, including WebPages that had allegedly been removed at the direction of the Trump administration. The Centre submitted its FOIA requests in late March and early April 2017.

In this case, the New York Attorney General Eric Schneiderman and Massachusetts Attorney General Maura Healey asked the federal district court for the Southern District of New York to dismiss Exxon Mobil Corporation's (Exxon's) action seeking to block their investigations into Exxon's climate change-related disclosures. Healey argued that a January 2017 decision in her favour by the Massachusetts Superior Court precluded Exxon from litigating its claims in federal court; that abstention was warranted under the Colorado River doctrine; and that Exxon's claims were not ripe because Exxon had and was pursuing an avenue for relief in state court. Healey also said that the New York federal court did not have personal jurisdiction over her. Schneiderman's motion to dismiss relied on the absence of ripe claims and the Colorado River abstention doctrine. Schneiderman contended that there was no ripe injury because his office's subpoena was not self-executing and Exxon had purported to have voluntarily complied with the subpoena. He also argued that the federal court should defer to the parallel state proceeding rather than allow Exxon to assert some objections to the investigation in federal court and others in state court. 51

On May 8, 2017, the Office of the New York State Attorney General served 10 subpoenas on Exxon Mobil Corporation (Exxon) in its

50 Center for Biological Diversity v. U.S. Department of InterioNo. 1:17-cv0974(D.D.C. filed May 23, 2017).

51 Exxon Mobil Corp.v. Schneiderman, No.1:17-cv-02301, S.D.N.Y. (May 19, 2017). 
investigation of Exxons climate change-related disclosures. One subpoena sought information and documents related to oil, gas, and other hydrocarbon projects approved, deferred, or declined by Exxon and proxy costs associated with those projects to reflect policies to stem greenhouse gas emissions. The subpoena also demanded information related to Exxon's decisions regarding impairment or write-downs for oil and gas projects and Exxon's estimates of its oil and gas reserves. In addition, the subpoena sought more recent documents responsive to the Attorney General's November 2015 subpoena and documents provided to the U.S. Securities and Exchange Commission in its climate change investigation of Exxon. The other nine subpoenas were testimonial subpoenas. On May 19, 2017, Exxon filed an order to show cause seeking to quash the document subpoena and four testimonial subpoenas that related to past subpoena compliance. Exxon argued that the Attorney General had not provided a factual basis to justify the demand for additional records and, moreover, that the Attorney General had impermissibly demanded that Exxon review and synthesize information and compile spreadsheets and summaries not already in existence. Exxon also contended that the Attorney General was probing areas foreclosed from state inquiry by federal regulation. On June 2, 2017, the Attorney General filed papers defending the subpoenas and cross-moving to compel. The Attorney General said in a brief and affirmation that the investigation had uncovered evidence of potentially false and misleading statements regarding Exxon's application of the proxy cost of greenhouse gases in its decision-making. The Attorney General argued that the new subpoenas were necessary to fill in gaps in Exxon's production of documents related to the company's risk-management practices, and that the testimonial subpoenas were also reasonably related to the investigation. The Attorney General disputed Exxons characterization of the subpoenas as unduly burdensome and as making improper demands for information. The Attorney General also argued that its prospective enforcement actions under New York's anti-fraud statutes were not subject to federal pre-emption. 52

52 People of State of New York v. Price Water House Coopers LLP, No.451962/2016, Sup. Ct. New York County (May 23, 2017). 
Four environmental organizations in this case filed a lawsuit in the federal district court for the Southern District of Ohio alleging that the U.S. Forest Service and U.S. Bureau of Land Management failed to comply with the National Environmental Policy Act (NEPA) when they authorized oil and gas leasing in the Wayne National Forest. The plaintiffs contended that the agencies relied on outdated analyses that did not take into account significant new information about climate change and other issues. In particular, they alleged that the documents upon which the agencies relied did not consider climate change effects on the forest or on species protected under the Endangered Species Act. ${ }^{53}$

Three petitions were filed in the California Supreme Court seeking review of the California Court of Appeal decision that upheld the state's cap-and-trade program for greenhouse gas emissions. The lead parties for the petitions were the California Chamber of Commerce, the National Association of Manufacturers, and Morning Star Packing Company. All three petitions asked the Supreme Court to review the question of whether the auction of greenhouse gas emissions constituted a tax that would need the approval of two-thirds of the California legislature under Proposition 13. The California Chamber of Commerce also asked the Supreme Court to review whether the California Air Resources Board's design of the cap-and-trade system was outside the authority granted to it by AB 32, the Global Warming Solutions Act. 54

\section{Paris Agreement and the Challenges}

The Paris Agreement established a new model in the global climate governance system by building an open-ended nationally driven bottom-up approach. Nonetheless, the triumph of the Paris Agreement will be determined by the extent to which country parties implement their commitments, goals, targets, binding obligations to mitigation and adaptation. This means that some

53 Center for Biological Diversity v. U.S. Forest Service, No. 2:17-cv-00372, S.D. Ohio (May 2, 2017).

54 California Chamber of Commerce v. State Air Resources Board, No. S241948 Cal. Chamber of Comm. petition (May 15, 2017). 
country parties to the Agreement would have to set up effective and significant climate action institutions. The Paris Agreement only created a template for the emerging climate change governance in terms of NDCs, stocktaking, ratcheting, reporting, updating and review. Country parties are therefore left to fashion out how the Paris Agreement will be implemented within their domain to achieve the overall goals of the documents. This involves domesticating the provisions of the Agreement within a designed elaborate framework, rules and procedures that will factor in the transparency mechanism, NDCs, guidelines for implementing the global stock take provisions, the review mechanism and the facilitative dialogue.

The Copenhagen Accord of 2009 agreed that the global temperature average should be limited to 2 degrees Celsius over pre-industrial levels. Since Copenhagen, experts and writers have stressed the dangers of a two-degree warmed world and the challenge of halting climate change. ${ }^{55} \mathrm{At}$ Paris, the COP21 announced limiting warming to 1.5 degrees Celsius. This has raised issues for the developing country parties and the several island countries that have declared that they cannot meet the ambitious target cuts they agreed prior to the COP21. Many have also argued that keeping warming below 1.5 degrees Celsius is near impossibility. To achieve the 1.5 degrees Celsius target by 2100, the country parties to the Paris Agreement need to stop emitting greenhouse gases into the atmosphere by 2060 .

Jen Schwartz has argued that despite the widespread celebration that accompanied the signing of the Paris Agreement, the truth is that the agreement amounts to little more than a gentleman's handshake. ${ }^{56}$ According to Schwartz, the terms are entirely enforceable, for one thing. And though the goals are laudable, it is ultimately too little, too late. ${ }^{57}$ David Richards further asked the question: But will the Agreement become binding international

55 Chris Mooney, The Magic Number: Holding Warming Under Two Degrees Celsius is the Goal. But is it Still Attainable?] The Washington Post (November 29 2015). (Last accessed on 15 June 2017)

56 Jen Schwartz, Why the Paris Climate Agreement, Cant Save the Planet Popular Science, Bonnier Corporation, (2016).

57 Id. 
law? And a greater issue is whether the treaty will remain binding. This article answers this question in the affirmative, because the Agreement has been ratified, adopted, or acceded to by over fiftyfive country parties that, together constitute above the fifty-five percent of global emissions. However, as argued above, the Kyoto Protocol has exposed just how fickle international climate change politics can be. The Kyoto Protocol at the onset received universal support, except from the United States, but facts have shown that less than one-fifth of its original signatories remained bound to its emission targets when the Protocol expired only seven years later. ${ }^{58}$

This article argues that the Paris Agreement is prone and susceptible to like tides of international climate change politics. The Agreement represents a compromise of sorts between the developed state parties and the developing nations. However, a mutual understanding between the world's greatest polluters contributed immensely to the success of the COP21 in reaching concord on a single document. In the coming years, it stands to be seen how the country parties will successfully build a working partnership with each other.

The challenges faced by the developing countries that are party to the agreement are real and their fears well-founded. India had argued during the Paris COP21 that the greenhouse gas emission arising from industrialized countries has already occupied twothirds of the carbon space in the atmosphere. Therefore, developing countries like India, which are just starting to develop their industries, cannot be restrained from avoiding emission. The argument is that it would be unfair for the developed country parties to put restriction on industrial development, just to avoid emission. This position finds reasoning on the strength of the fact that the developing country parties were underdeveloped by the rich countries of the West who deprived them of the benefits of the Industrial Revolution. It is on this score that the financing mechanism was built into the Paris Agreement in order to help the developing country parties achieve climate change action implementation, thus, the USD100 billion per annum that would be

$58 I d$. 
raised by the rich country parties by 2020 to actualize the overall goal of COP21 in the developing nations.

In as much as the developing countries are hesitating to cooperate in limiting the rise in average global temperature by mitigating greenhouse gas emissions, the finances and budget of these countries, does not represent or see a boost for climate change. This has hoisted a very big challenge on improving mitigation and adaptation. Meeting the Paris Agreement commitments is tied to the availability of financial resources and this is not really forthcoming for the developing countries. The capacity is lacking due to constant tribal, religious, political and terrorism, conflicts faced by these developing countries. Therefore, it remains to be seen how the developing countries will achieve the target cuts in greenhouse gas emission.

Another great challenge is that not all aspects of the Paris Agreement are legally binding, only some provisions contained in the document, thus, creating problem for failure to fulfil their obligations. On this score, it means that the developed countries are not bound to provide sufficient financing to implement mitigation and adaptation activities for ensuring climate-resilient development. Should this be the case, the developing countries then face a big challenge in pursuing their national mitigation and adaptation activities to tackle the adverse impacts of climate change within their domain. It is true that the Paris Agreement mentions the necessity of initiating approaches to secure private sector participation in its implementation, mostly in the area of technology development and transfer, but the Agreement failed to specifically cite intellectual Property Rights (IPR). This leaves a gap in protecting the knowledge and the new technology discovered through research and development. This is so, because the private sector is profit-driven and must be motivated to invest in this sector if proper achievement must be made in this regard. Therefore, lack of incentives and intellectual property rights poses a challenge for the private sector to effectively participate in the implementation of the Paris Agreement.

The author is of the view that though the Warsaw International Mechanism for Loss and Damage associated with Climate Change Impacts was recognized by the Paris Agreement, the practicability 
of paying compensation to affected peoples or countries was not recognized. Also, though the Agreement recognized the link between human rights and climate change impacts, it imposes no obligations as regards relocation contained in the Agreement to address the rights of the people vulnerable to displacement This article argues that the developing nations and the least developed countries of the Paris Agreement are presently facing challenges in articulating their National Adaptation Plans (NAPs), due to scarcity of funds. These vulnerable countries are bound to experience the grave aftermath of climate change impacts without availability of financial resources to implement NAPs and NDCs.

The Paris Agreement also failed to address ways of ensuring compliance with effective and efficient implementation. The Agreement is non-punitive in nature as there is no intention of inflicting punishment on countries that do not comply with its provisions. This is a restraining element in attaining the overall goal of limiting the greenhouse gas emission to 1.5 degrees Celsius. This article argues that there is need for the countries that are party to the Agreement to reach a further agreement, by consensus, on a fully legally binding framework. This is necessary, because without appropriate compliance measures and enforcement mechanism, the pre-2020 and post-2020 climate action would not only be a mirage but unachievable.

\section{The Impact of Climate Change on Small Island Nations and Developing Countries}

Small island nations are dotted around the world. The bulk of the small island countries are occupied by humans while others are uninhabited. ${ }^{59}$ There are over 20,000 of the small islands in the Pacific Ocean. The total population of the small islands of the Pacific is estimated at 5-6 million inhabitants, out of that

59 Van Alphen, K., H.S. Kunz, and M.P. Hekkert: Policy Measures to Promote the Widespread Utilization of Renewable Energy Technologies for Electricity Generation in the Maldives, 12(7)Renewable and Sustainable Energy Reviews, 1959-1973 (2008). 
population, two thirds live in Papua New Guinea.60 However, countries including Japan, Hawaii, the Philippines, New Zealand, Tasmania, and the Indonesian islands are mostly regarded as distinct group of smaller islands. Many of the small island nations have delicate economies and may not be able to bear the costs of adjusting to climate change. Topmost on the list of possible impacts of climate change is the risk of losing the entire islands to rising sea levels, ${ }^{61}$ that may submerge the territories and exacerbate storm surges accompanied by the risks of tidal waves causing erosion and destroying the nation's infrastructure and occupational livelihoods.

For islands that may not erode completely or submerged, the risk of losing the sources of freshwater resources is foreseeable. On the Pacific atoll of Tarawa, a predicted $10 \%$ reduction in rainfall by 2050 , if it occurs, will cause a $20 \%$ shrinkage of the freshwater lens. ${ }^{62}$ In summary, the danger of climate change is likely to affect the followings:

Tourism, fisheries, agriculture, and human health will be adversely affected by climate change. For example, coral reefs are already being destroyed by warmer temperatures in tropical waters around the world. Fish populations and thus fish catches by island populations decline sharply when coral reefs shrink. ${ }^{63}$

On the effects on the developing economies, the Paris Agreement acknowledges the weakness of the economic structures and poor governance infrastructure in the developing countries. In this regard, the balanced approach between mitigation and adaptation has been structured in such ways that, the developing countries and the least developed countries can gain access to international

60 Gilman Eric, Owens Matthew, Kraft Thomas, Ecological risk Assessment of the Marshall Islands Longline Tuna Fishery, 44 Marine Policy, 239-55 (2014).

$61 \mathrm{~J} \mathrm{~K} \mathrm{Willis} \mathrm{and} \mathrm{J} \mathrm{A} \mathrm{Church,} \mathrm{Regional} \mathrm{Sea-Level} \mathrm{Projection,} \mathrm{Science,}$ 336(6081), 550-551 (2012).

62 Patel Samir S, Climate science: A Sinking Feeling, Nature, 734-6, (2006).

63 F S Whyte, M A Taylor, T S Stephenson, and J D Campbell: Features of the Caribbean Low Level Jet, 28(1)International Journal of Climatology, 119-128 (2008). 
climate funds to enable them to comply with the adaptation needs as stipulated in the Paris Agreement. ${ }^{64}$ For instance, Article 6(6) of the Paris Agreement provides that the procedure of internationally transferred mitigation outcomes, that is voluntary and tailored towards achieving nationally determined contribution shall assist in generating earnings which can be used to cover the administrative costs, and also assist the developing countries, particularly vulnerable countries, to meet the costs of adaptation. 65 On face value, the Paris Agreement seems to make projections that may be of huge advantages to the developing nations and the least developed nations (including the island nations).

\section{Efforts Taken For Implementation of Climate Change Measures}

Despite the aforementioned shortcomings, some countries have commenced efforts towards actualizing the goals of the Paris Agreement.66 In Africa, Kenyan stakeholders have explored implementation of the Paris Agreement. Kenyan government established the Climate Change Directorate under the Ministry of Environment and Natural Resources on 13 December 2016.67 The goal of the agency is to implement the 22nd United Nations

${ }^{64}$ Ladan, Muhammed Tawfiq, Review of the Paris Agreement: The Heart of the Post-2020 International Legal Regime on Climate Change and its Implications for Sustainable Development Goals and the Energy Sectorhttps://ssrn.com/abstract=2814652, retrieved 25 July 2017(Last accessed on June 22 2017)

65 Suarez Irene and Huang Jennifer, Addressing Adaptation in a 2015 Climate Agreement. Center for Climate and Energy Solutions (2015) https:// ssrn.com/abstract=2724613(Last accessed on 25 July 2017).

66 Taylor, M A, F S Whyte, T S Stephenson and J D Campbell,Why dry? Investigating the Future Evolution of the Caribbean Low Level Jet to Explain Projected Caribbean Drying. International Journal of Climatology, 33(3), 784-792, (2013).

${ }^{67}$ Tkachenko K S; The Northernmost Coral Frontier of the Maldives: the Coral Reefs of Ihavandippolu Atoll Under Long-Term Environmental Change. Marine Environmental Research, 82, 40-48,(2012). Also in Tompkins E L, M C Lemos and E. Boyd; A Less Disastrous Disaster: Managing Response To Climate-Driven Hazards in the Cayman Islands and NE Brazil, Global Environmental Change, 18(4), 736-745 (2008). 
Framework Convention on Climate Change Conference of Parties (COP22) and identify the specific programmes of action. ${ }^{68}$

The Kenyan government has also engaged civil society organization and embarked on research projects designed to find ways and measures of implementing the Paris agreement. ${ }^{69}$ The National Gender and Equality Commission is now working actively to progress the implementation of gender-responsive climate policies and mandates across all areas of the negotiations within a timeframe of 3 years..$^{70}$ Also, the Kenya Private Sector Alliance (KEPSA), is working on developing hardware for the adaptation and mitigation. ${ }^{71}$ The government has also formed an agency known as the Nationally Determined Contributions (NDCs) tasked with the responsibility of implementing the policies on emissions and elimination of poverty from the grassroots, particularly focusing on rural development. ${ }^{72}$

Elsewhere, in line with the voluntary obligation that, countries should submit full national climate action plans. The European Union (EU) was the first regional body to comply with the commitment. It earmarked the regional emissions decrease target to $40 \%$ by 2030 .The EU has also pledge its supports to the developing countries. The EU vowed to partner with many other industrialized countries to support climate action aimed at reducing emissions and build pliability to climate change effects in developing countries by following their present communal targets of mustering USD 100 billion per year by 2020 and outspreading this to 2025, when a new objective shall be formulated.

$68 I d$, at 12.

69 Government of Kenya, Kenya Vision 2030; Nairobi: The Government of Kenya (2017).

70 UNEP. Kenya: Atlas of Our Changing Environment. Division of Early Warning and Assessment (DEWA); Nairobi (2009).

71 Obati G O P, The Impacts of ENSO in Africa, In Low P S, (Ed.) Climate Change and Africa, Cambridge University Press, Cambridge, 218-230 (2005).

$72 \mathrm{Id}$, at 220 . 


\section{Conclusion}

The Paris Agreement is a significant milestone in the annals of climate action development. It came at a time when all hopes of tackling climate change impacts had dimmed due to the almost total failure of the previous Agreements and Protocols on climate change. Parties to the COP21 had feared the Paris Agreement would not be a reality and might go the way of Copenhagen Accord where there was a breakdown in talks. The Paris Agreement has rekindled hope and confidence in the international climate change regime. The Agreement is a momentous success despite its short-comings and fears. The diplomatic skill employed during negotiations created sufficient opportunities for countries to negotiate and explore areas of common interest and concern to their nationalities and regional blocks, particularly in the area of their intended Nationally Determined Contributions (NDCs). The Agreements ambitious target of reducing the global temperature rise to 1.5 degree Celsius and net zero emissions between 2050 and 2100 remain significant. The inclusion of non-state actors and stakeholders into the scheme of events is very remarkable and has created a new approach in tackling the climate action challenge. For the first time in the history of climate change regime, there was a concordant voice on a single document on the urgent need to for scaling up ambition.

However, it is not all praises for the Agreement. There are several grey and negative areas, one of which is the expunging of historical responsibility from the final text of the Agreement which has therefore watered down the legitimate expectation of the developing countries on the obligations and responsibilities that the developed countries owe to them. This article however argues that the phrase was never contained in the UNFCCC but was only mildly captured in its Preamble that the developed world has the largest share of greenhouse gas emissions. Another sore area in the Agreement is its failure to retain the liability and compensation clause in the loss and damage provision. This effect has again watered down the mechanism to the disillusionment of the most vulnerable countries. There is also the lack of strong legal commitment that the developing countries would receive funding, technology transfer, and capacity building required to help them in 
their adaption and mitigation efforts, thus posing a big problem in the implementation of the Agreement.

The Agreement, to enter into force, requires ratification by at least 55 per cent of the countries that are party to the UNFCCC which represents 55 per cent of total global greenhouse gases emissions, in other words, the implication is that once the Agreement is adopted it becomes legally binding. In this circumstance, all the countries that have signed the Agreement and consented to join and be bound by its provisions are legally bound by its provisions and are legally bound the Agreement. The downside to this provision of the Agreement is that not being a protocol or treaty, it contains no strict legally binding provisions. Thus, though the countries have agreed to undertake and communicate their NDCs, covering mitigation, adaptation, finance, technology, capacity building and transparency, they are likely to exploit the loopholes contained in the Agreement. An example of such a loophole is the provision that requires countries to submit new emission reduction targets every five years, to regularly submit information regarding how they are tracking towards achieving those targets as well as submitting this information to a technical expert review, but they are not required to achieve the commitment targets they have set. Only certain provisions of the Agreement are legally binding, and unfortunately the most important provision requiring the developed countries to mobilize USD100 billion each year by 2020 for mitigation and adaptation efforts and additional funding beyond 2020 is not legally binding. Furthermore, countries have to wait for future developments such as establishing mechanisms that could give teeth to the legally binding nature of the Agreement. This has resulted in the setting up of a Compliance Committee, but presently, the certainty of the Committee's mandate and powers are not clear.

This author argues that it does not matter whether the Agreement is legally binding or not, the important point is the commitment by the countries to work towards the implementation of the deal, and refrain from indulging in acts that could potentially defeat the object and purpose of the agreement. In this manner, it is expected that the countries should chart the way forward for the facilitative dialogue due in 2018, that would take stock of progress so far 
made, to achieve the long-term mitigation goal of the Agreement. The Agreement has created opportunities and challenges to the developed and developing countries in different forms, it is therefore necessary for developing countries to appreciate and understand the main opportunities and challenges contained in the Agreement. 